\title{
AS ESTRATÉGIAS DE MARKETING POLÍTICO NO PROCESSO ELEITORAL DE UMA UNIVERSIDADE
}

Raphaela Pereira Rangel (UFRRJ) rangelufrrj@hotmail.como Jorge Alberto Velloso Saldanha (UFRRJ) javsa@ terra.com.br

\section{Resumo}

Muitas pesquisas sobre o tema de marketing político tentam evidenciar a sua relação com a política. O presente estudo tem como objetivo identificar as estratégias de marketing político, apresentando as ações adotadas por alguns candidatos, a fim de tornar mais claro como essas ferramentas podem favorecer, ou não, uma candidatura. Para tanto, a pesquisa foi desenvolvida por meio do método qualitativo, com o uso de entrevistas em profundidade com os membros das chapas candidatas a reitoria de uma universidade. Os resultados obtidos demonstram que muitos candidatos não possuem conhecimento sobre o processo eleitoral dentro da própria sociedade acadêmica que estão inseridos, e também que a mesma, tem uma necessidade de criar novos meios de comunicação interna.

Palavras-Chave: Marketing Político; estratégias de marketing; processo eleitoral

\section{Introdução}

As eleições nacionais de 2018, contaram com o uso massivo da internet. Eleitores, assim como partidos e candidatos tiveram a oportunidade de discutir seus diferentes pontos de vista nas redes sociais. Essas "trocas" de informações e até discussões sobre a eleição não se mantiveram apenas de forma digital. Nas ruas e nos locais públicos muitas foram as discussões sobre a política no Brasil.

As universidades brasileiras também tiveram em seus centros educacionais muitos debates sobre a política nacional, seja nas conversas de corredores, em discussões na sala de aula ou até em debates organizados por estas para que os candidatos pudessem expor suas ideias à comunidade acadêmica.

Assim como, em pleitos nacionais, nas universidades brasileiras, o processo eleitoral é semelhante. No entanto, cabe ressaltar que, em alguns casos, o processo eleitoral dessas instituições, não ganham a mesma importância que as campanhas políticas nacionais que são tão discutidas nesses mesmos centros educacionais. 
As instituições públicas de ensino superior são igualmente importantes, salvo as devidas proporções, elas têm a responsabilidade de gerar conhecimento e formar cidadãos capacitados para o mercado de trabalho, contribuindo para o bem social. O objetivo principal desse trabalho é identificar como o marketing político é praticado durante as campanhas eleitorais para a reitoria de uma universidade pública brasileira.

Para tanto, foram entrevistados os candidatos a reitoria nas eleições de 2016 (última realizada), a fim de investigar como se desenvolve o processo eleitoral na universidade, como os grupos políticos se formam e como as chapas concorrentes se organizam e veem a comunicação eleitoral.

\section{Fundamentação teórica}

\subsection{Marketing Político}

Rubens Figueiredo (1994, p.10), define o Marketing Político como um "conjunto de técnicas e procedimentos que têm como objetivos 'adequar' um candidato ao seu eleitorado potencial, procurando torná-lo conhecido e com um maior número de eleitores possível, e em seguida, mostrando-o diferente de seus adversários, melhor do que eles”.

Nessa mesma perspectiva, Ribeiro (2002), conceitua como um "conjunto de técnicas de persuasão política e procedimentos de natureza estratégica voltados para a disputa pelo controle da opinião pública, ou tentativa de domínio da recepção das imagens públicas”.

Enquanto que, Scotto (2003), considera o marketing político como um fenômeno social, no qual, quando estudado, é possível ter acesso à interseção entre campos como política e mercado. Conforme Scotto (2003, p.75), “quando se questiona a dicotomia mercado versus política, e se olha em contrapartida, para pontos de encontro entre ambas 'esferas'.

\subsection{Marketing Político e Marketing Eleitoral}

O marketing político e o marketing eleitoral são comumente confundidos ao serem citados, inclusive em algumas pesquisas acadêmicas. Portanto, se faz necessário para esse estudo a diferenciação dos termos.

Conforme Almeida e Sette (2010, p.6), o marketing político "está relacionado com a formação de imagem de longo prazo, é algo mais permanente", enquanto o marketing eleitoral seria algo de "curto prazo". Para os autores, “o marketing político é uma ferramenta de manutenção da popularidade e o marketing eleitoral é uma ferramenta comunicacional 
utilizada nos processos eleitorais, que tem por premissa o convencimento do eleitor à decisão do voto por este ou aquele candidato" (ALMEIDA; SETTE, 2010, p.6).

Rubens Figueiredo (1994, p.11), fundamenta que além do marketing político ser algo mais permanente, ele ocorre quando o "político no poder se preocupa em sintonizar sua administração com os anseios dos cidadãos”, portanto, um trabalho a longo prazo. Enquanto que, o marketing eleitoral "aparece na hora do 'vamos ver', enquanto todos os candidatos saem à procura de um mandato".

Almeida e Sette (2010, p.7), salientam a importância de se definir corretamente os termos político e eleitoral sem que esses conceitos sejam separados ou que se oponham. De acordo com os autores, "apesar de existir essa distinção teórica, os profissionais de marketing que atuam na política não a utilizam, usando o termo marketing político para designar ambas as abordagens, o que vem a reafirmar a ligação indissolúvel” (ALMEIDA; SETTE,2010, p.9).

Nessa mesma perspectiva, Teixeira (2006), explica que, ainda que sejam conceitos distintos, existe uma "relação de interdependência" entre eles, uma vez que, para que haja estratégias de marketing eleitoral se faz necessário um planejamento a longo prazo através do marketing político.

\section{Metodologia}

A pesquisa foi desenvolvida por meio do método qualitativo, justificado por ser de natureza exploratória, baseado em uma amostra, utilizando a técnica qualitativa da entrevista em profundidade (MALHOTRA, 2011).

O critério de seleção utilizado foi por conveniência (não-probabilístico), uma vez que os indivíduos atendem aos critérios e são de fácil acesso ao investigador e, considerando o processo de "saturação teórica", que consiste na "realização progressiva das entrevistas até o ponto em que os dados obtidos vão se tornando repetitivos" (GIL, 2010).

Foram entrevistados durante a pesquisa de campo, doze candidatos que participaram nas quatro chapas que concorreram nas eleições para a reitoria da universidade pública em estudo, em 2016.

As perguntam foram elaboradas, após a observância dos dados levantados pelas pesquisas bibliográfica e documental, formando um questionário composto por trinta e uma perguntas, 
que abordam questões como a forma que os candidatos veem marketing dentro do processo eleitoral e as estratégias de marketing político utilizadas durante as campanhas.

A análise dos dados ocorreu por meio da consolidação das respostas das entrevistas individuais aplicados com os dados obtidos na pesquisa bibliográfica e documental, através da Análise de Conteúdo, com o objetivo de estabelecer conclusões.

Também para a análise do texto, foi utilizado o software NVivo®, para potencializar a exploração dos dados obtidos nas entrevistas, bem como organizá-los. O software NVivo® "consiste num sistema de indexação e de categorização de dados não-estruturados, o que possibilita a descoberta e a exploração dos sentidos das informações alfanuméricas" (MOZZATO; GRYBOVSCKI, TEIXEIRA, 2016).

Como limitação do trabalho, cita-se a pouca experiência dos entrevistados com alguns conceitos presentes nesta pesquisa, o que configurou um ponto de atenção por parte dos autores.

\section{Análise de dados}

As entrevistas foram realizadas de forma individuais, face a face com os entrevistados na sede da universidade, especificamente nos institutos respectivos de cada entrevistado, durante dois meses. Os entrevistados foram identificados através de um código alfanumérico. A letra "E" de entrevistado e seguido de um número que representa uma ordem aleatória escolhida por meio de sorteio, apenas para distinguir um participante do outro e preservar o anonimato.

As perguntas foram desenvolvidas com o intuito de conhecer melhor a opinião dos entrevistados sobre as estratégias de marketing político que foram praticadas nas campanhas eleitorais para reitoria.

Questionados sobre o planejamento estratégico das ações de marketing político, os entrevistados, em sua maioria, esclareceram que em suas chapas não tinham profissionais responsáveis por essas ações, no mais, tinham colegas simpatizantes às chapas que se ofereceram para ajudá-los:

"As ações de comunicação e divulgação da chapa foram discutidas em grupo e com esses alunos que acompanhavam o trabalho de forma mais 'profissional'. Eles se engajaram com o trabalho mais direcionado para essa divulgação (E04).” 
“As coisas foram acontecendo, assim a nossa chapa foi montada muito em cima da eleição; quer dizer, eu acredito que a dois meses da eleição é que nós conseguimos montar a chapa. Então, assim, nós fomos construindo aos poucos. O caminho de faz ao caminhar (E05)”.

Através da Figura 1, é possível, de forma sintética, verificar as palavras que mais se repetem nas respostas dos candidatos, questionados se tiveram algum tipo de planejamento estratégico com o uso de marketing político na campanha.

Figura 1 - Nuvem de palavras sobre o planejamento estratégico de marketing político

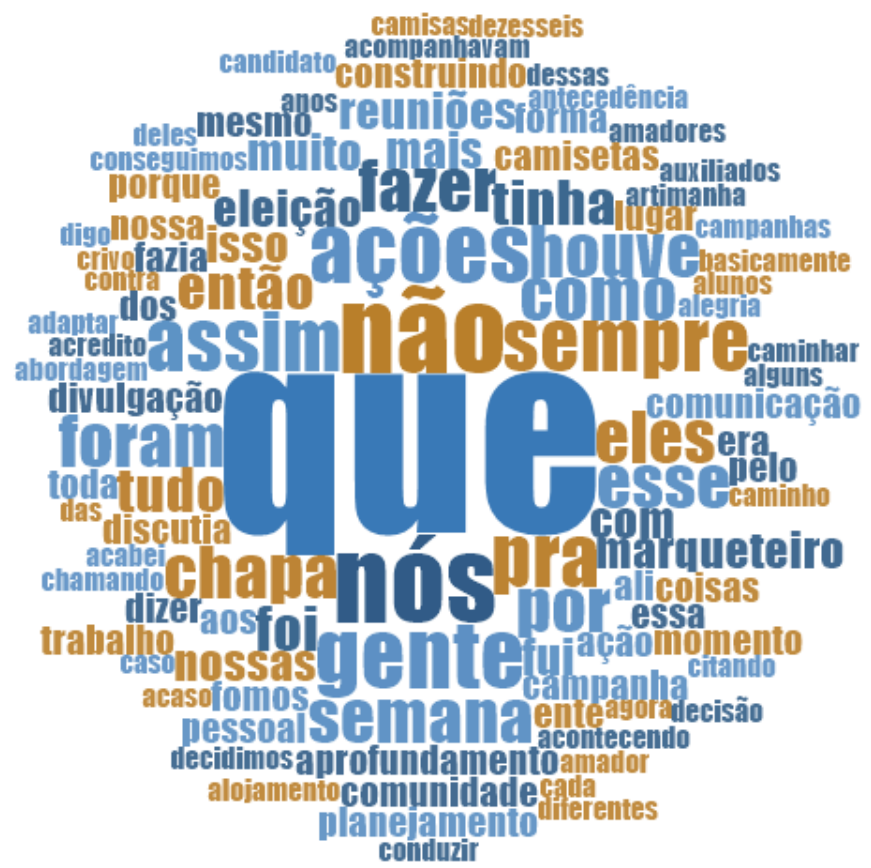

Fonte: Elaborada pelos autores através do software NVivo® (2019).

Com o objetivo de investigar o que entendem como marketing político, os entrevistados foram indagados se fizeram uso de alguma ação que consideram como estratégias de marketing político:

“Sim. Nós tínhamos um... nós tínhamos uma página dentro das... redes sociais, e ali nós postávamos, nós colocávamos nossas ideias entendeu? Até porque muitos institutos, muitos departamentos, se quer nos receberam, justamente por ser reduto político de outras chapas (E12)”.

"Eu tenho dificuldade na área de marketing, mas acredito que sim. O slogam, né? O nosso slogam tinha um marketing ali, que a gente construiu várias e as pessoas da área é que falaram: 'não, esse aqui é melhor por causa disso, daquilo' (E07)". 
Como a maioria dos entrevistados é professor de diversas áreas de conhecimento, alguns deles deixaram claro que não saberiam dizer se aquelas ações são realmente estratégias de marketing político, mas esclarecem que, de forma quase unânime, utilizara-se de propagandas nas redes sociais, através do envio de mensagens por e-mail e por aplicativos de mensagens instantâneas, criação de vídeos em que os candidatos divulgam suas propostas e que foram publicados em plataformas sociais, assim como nos sites oficiais das chapas. E as chapas confeccionavam faixas e distribuíam panfletos.

A Figura 2, resume sinteticamente as palavras que mais se repetiram nas falas dos entrevistados quando foram questionados sobre as estratégias que consideram como marketing político em sua campanha.

Figura 2 - Nuvem de palavras sobre as estratégias consideradas como marketing político.

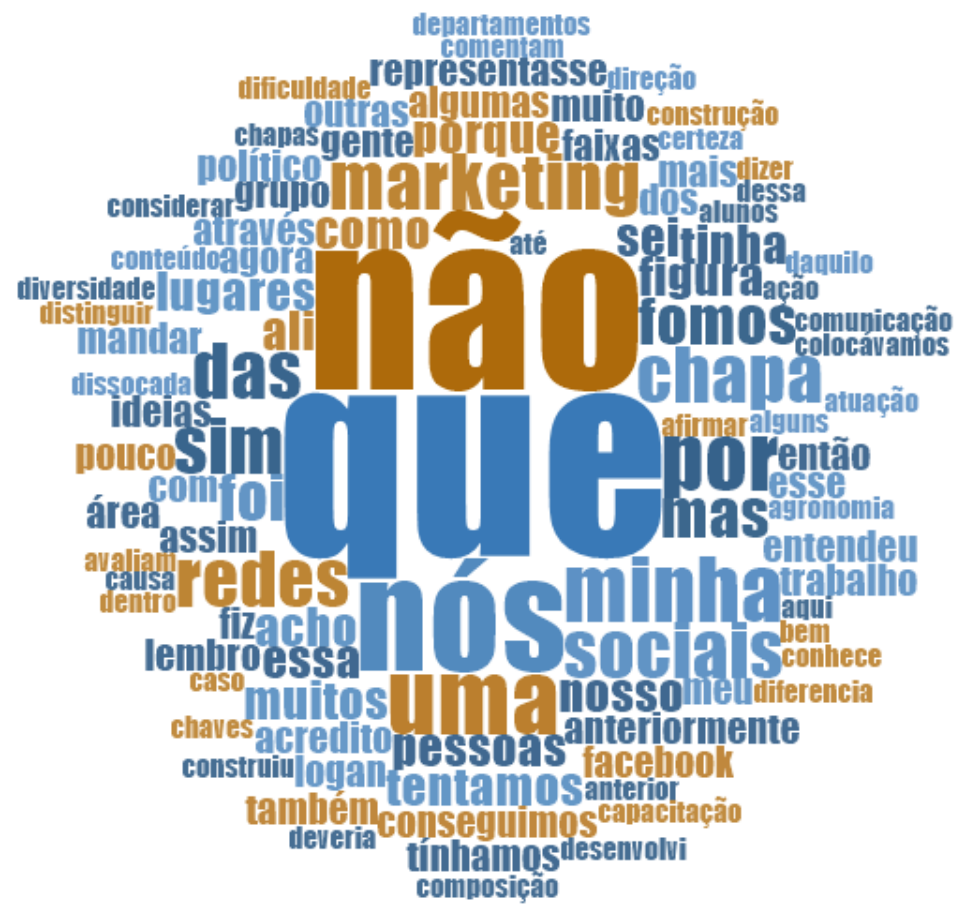

Fonte: Elaborada pelos autores através do software NVivo® (2019).

Na mesma perspectiva da pergunta anterior, a questão subsequente tentou identificar algumas das estratégias planejadas pelas chapas, como a criação de slogans, músicas e camisetas, e outras ações de publicidade.

"Nós, fizemos. Isso eu posso garantir, nós fizemos. Nós éramos muito bem abastecidos de camisa, de cartãozinho, de panfletos. Houve uma grande divulgação de painéis com as nossas fotos. Nós passamos a ser conhecidos. Eu que não era muito conhecido passei a ser conhecido. É, nós usamos músicas de... de... músicas de rádio que serviram como estímulo, 
né, pro grupo, pra gente e as atividades e tudo. Mas, assim, se isso é marketing político, eu não posso te garantir (E01)".

"Então, nós levamos tudo, as pessoas levavam as suas camisas e a gente fazia com quem tava na hora, né? Na tela. Eu achei aquilo ali fantástico. Porque foi uma coisa assim, era uma oportunidade que a gente tinha de discutir o programa, de fazer a campanha né, e disseminar o slogan pelos estudantes, e de tá próxima a eles, ouvir um pouco mais do que eles pensavam nos outros programas e tal. Os panfletos específicos pra docentes, pra técnico-administrativo, pra discente, uma estratégia que a gente usou. É, o que mais? Aquele 'login' que cola na camiseta também, bonitinho; fizemos uma coisa que eu achei lindinha [...], mas o principal é a pintura das camisas que achei legal (E07)".

A Figura 3, de forma sintética, apresenta um pouco sobre a publicidade produzida pelos candidatos, que contaram com produção de panfletos, cartões, painéis, faixas, músicas, materiais plásticos, jornais, adesivos, carros adesivados circulando pelo campus, e distribuição de camisetas e uso da confecção dessas camisetas como estratégia à parte.

Figura 3 - Nuvem de palavras sobre a preocupação com o uso do Marketing Político

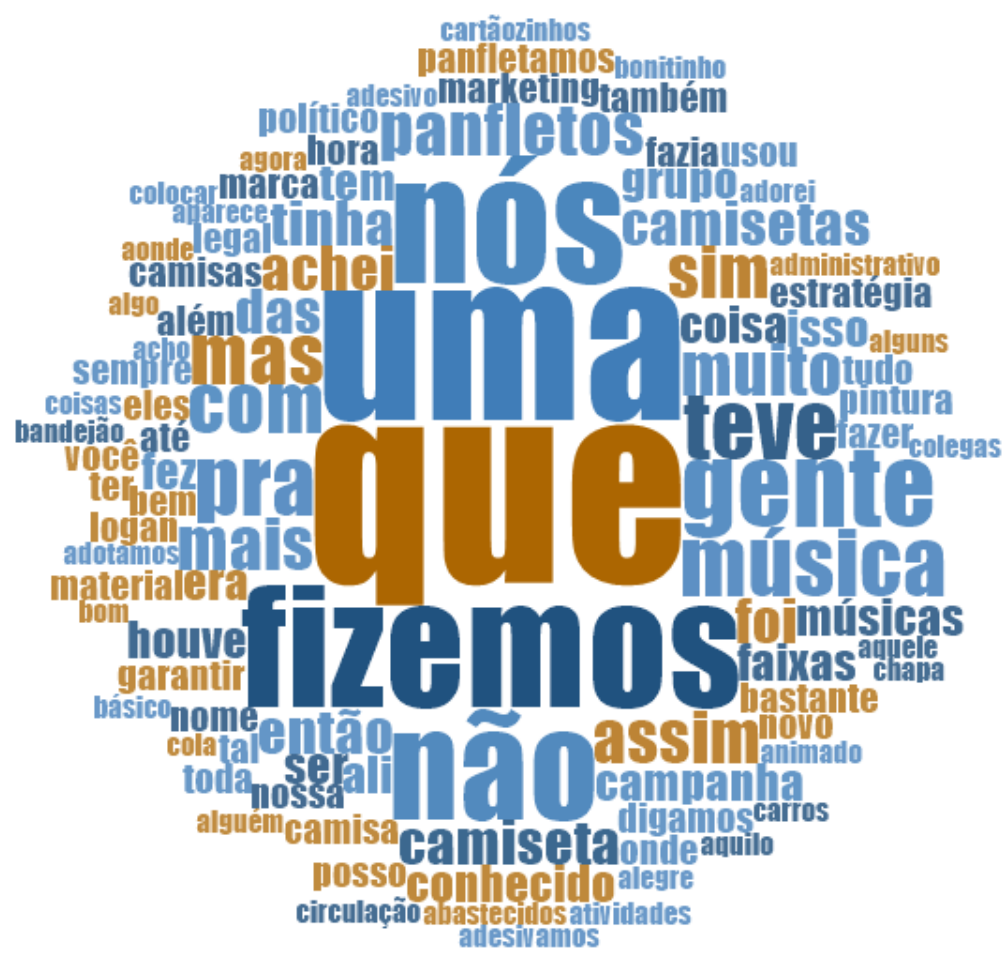

Fonte: Elaborada pelos autores através do software NVivo® (2019).

De forma objetiva, ainda foi questionado a cada entrevistado como que a sua chapa praticou o marketing político durante a campanha eleitoral. Essa questão obteve as mais diversas 
opiniões. Há aquele que diga que não se interessou muito em como o marketing político foi estruturado, pois estava envolvido em outras frentes. Outro reconheceu que sua chapa praticou um marketing político que ele considera "antiquando". Já outro entrevistado reconheceu que sua chapa atuou de forma amadora pois não se preocuparam com uma análise prévia de suas ações. E há os que defenderam que sua chapa praticou o marketing político através de reuniões, panfletos, faixas, papéis, contatos políticos, divulgação, banners, mas principalmente através das suas redes sociais. Em sua maioria, os entrevistados citam as redes sociais como o principal meio de comunicação e divulgação. Alguns chegaram a defender, também, que o papel das redes sociais tende a aumentar nas próximas eleições.

“Bom, na verdade, eu não sei se essa divulgação no Facebook é... considerado marketing político. Então, a gente tentou através dessa divulgação nos meios digitais. Hoje... A gente não tinha tanto a questão do WhatsApp, mas houve, né, lógico, também a ação de envio de material, proposta. Mas eu acho que o marketing político importante foi a gente divulgar através de panfletos, enfim, de material impresso quais eram os nossos objetivos; nossas metas; e as ações que a gente queria desenvolver dentro de cada pró-reitoria (E11).”

"O marketing político foi utilizado da seguinte forma: via rede social Facebook. Alguns participantes da chapa, como eu também enviaram propaganda da chapa via WhatsApp pra seus pares. Além disso, foram feitas dezenas de faixas, painéis, mas infelizmente esses foram vandalizados. Na realidade, o marketing via painéis foi o primeiro meio a ser utilizado, antes mesmo da chapa ter sido completamente fechada com todos os integrantes. Panfletagem em pontos estratégicos e o corpo a corpo em diversos setores expondo as propostas e respondendo questões levantadas pelos ouvintes (E12)".

A Figura 4, sintetiza as palavras mais repetidas nas falas dos entrevistados quando questionados sobre como sua chapa praticou o marketing político.

Figura 4 - Nuvem de palavras sobre a prática do marketing político 


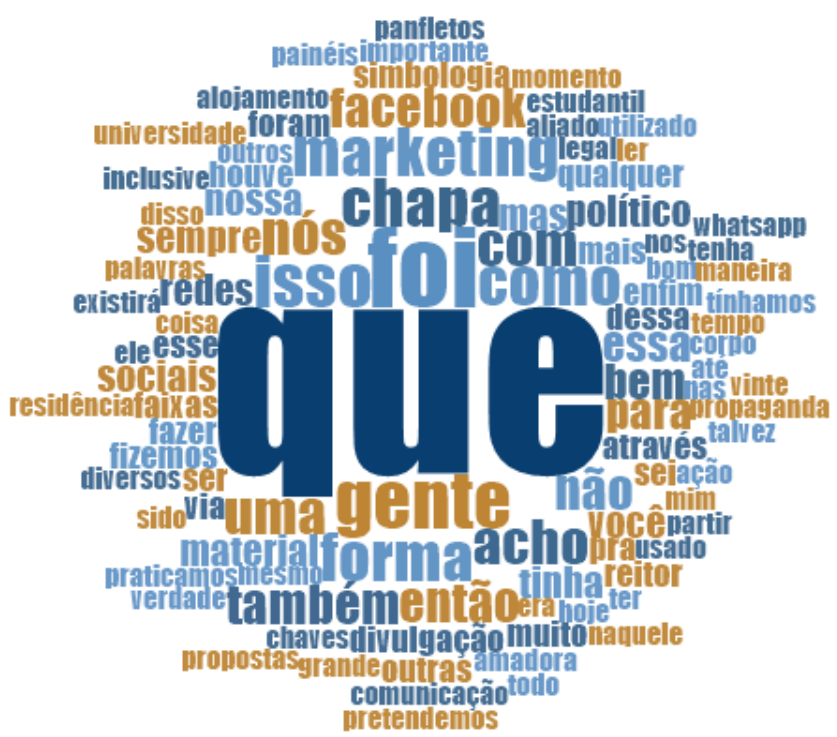

Fonte: Elaborada pelos autores através do software NVivo® (2019).

Quanto à influência da prática do marketing político dentro da universidade, foi questionado aos entrevistados se eles acreditavam que esse marketing político seria, realmente, capaz de influenciar de forma positiva ou negativa a intenção de votos dos eleitores:

"Pois é, o marketing político discreto e comunicativo, que leve realmente a informação e a mensagem propositiva, eu sinto que é marketing que aumenta o número de votos, que leva ao resultado positivo. Mas, nas universidades, o que eu vejo é que o marketing político que é feito, é de desconstrução de pessoas, como acontece no... como aconteceu nas eleições de dois mil e dezesseis (E05).”

"Pode. Com toda certeza, né? O que eu falei, positivo é quando você consegue passar pra pessoa quem é você, tá? Negativo, é quando essas, outros grupos, utilizam de artimanhas, como, por exemplo, tem pessoas que regavam festas a cervejas paga por eles para os alunos poderem fazer a campanha contra. Então, chama os alunos, paga cerveja pra esses alunos agirem como marketing político contrário a essas outras chapas (E06)."

Em relação aos candidatos, mais uma vez, em maioria eles acreditam não só influência "com certeza", como também destacam a força da influência de um marketing político mais "mentiroso", como em casos de "Fake News".

Esse tipo de marketing político que desconstrói algo ou alguém, foi muitas vezes mencionado nas entrevistas independente de qual era a chapa do candidato, evidenciando um receio por partes dos entrevistados que participaram do processo eleitoral para a reitoria da universidade. 
Através da Figura 5, é possível verificar nas respostas dos entrevistados as palavras que mais se repetem nas respostas dos entrevistados quando questionados se acreditam que o uso do marketing político pode influenciar de forma positiva ou negativa os votos dos eleitores dentro da própria universidade.

Figura 5 - Nuvem de palavras sobre a influência do marketing político

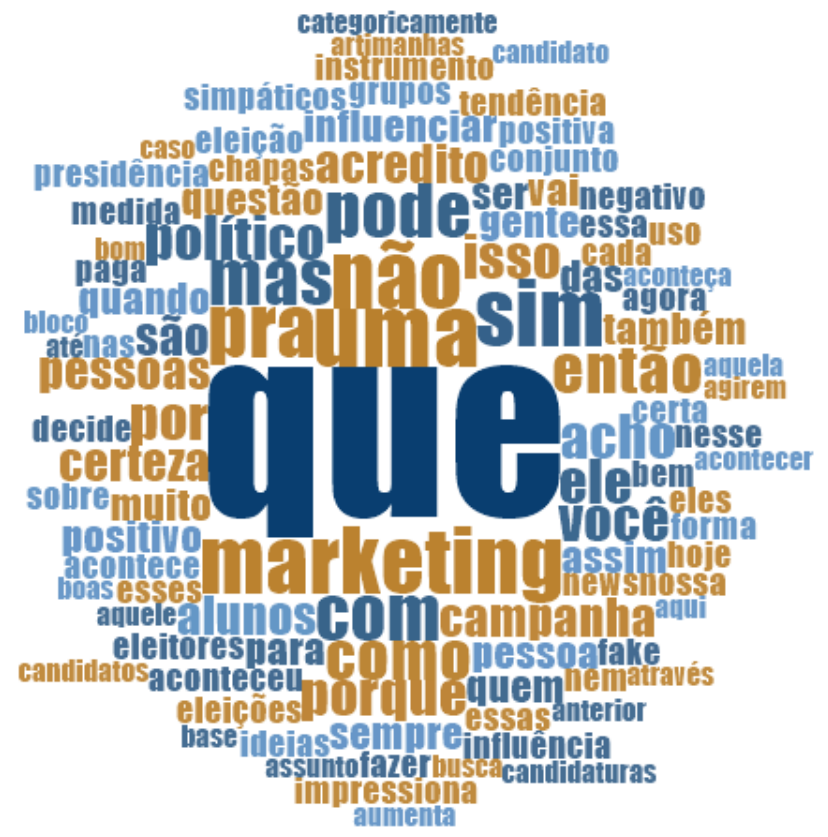

Fonte: Elaborada pelos autores através do software NVivo® (2019).

\section{Considerações Finais}

O presente estudo identificou como o marketing político é praticado pelos grupos políticos dentro de uma universidade pública. Atendendo a esse objetivo, a pesquisa objetivou investigar a percepção dos candidatos sobre o uso do marketing político nas campanhas para a reitoria da universidade. Os dados obtidos através das entrevistas corroboram com as ideias desenvolvidas no estudo e enriqueceram a pesquisa, trazendo percepções diferentes sobre o mesmo processo eleitoral.

Os entrevistados esboçaram as mais diversas opiniões sobre a prática do marketing político no processo eleitoral dentro da universidade. Em geral, os entrevistados defendem que por mais que as chapas se empenhem, o marketing pode ser considerado amador, tendo em vista a inexperiência de alguns candidatos em lidar com problemas ao longo do percurso, inclusive reconhecem que cometeram "erros", não valorizando o marketing durante a campanha. Ao 
mesmo tempo, há quem defenda que esse "amadorismo" faz parte do processo, e é o que o diferencia de um processo eleitoral comum.

De acordo com os entrevistados, o marketing político é praticado através da distribuição de panfletos, divulgação de banners e faixas, contato direto com os eleitores, o chamado "corpo a corpo" com o intuito de divulgar melhor a chapa, além de outros materiais, e principalmente mantendo a comunicação com os eleitores através das redes sociais. Os entrevistados esclareceram que as chapas procuraram se diferenciar das demais concorrentes, mas deixam claro que, quase sempre, as chapas dispunham de recursos para isso.

Além disso, através da entrevista com os candidatos, foi possível constatar que existem muitas dúvidas sobre o processo eleitoral que eles mesmo fazem parte, inclusive quem seria o responsável pela organização do processo. Sendo assim, recomenda-se a criação de uma Comissão Eleitoral para que de continuidade aos processos eleitorais de forma mais ética e transparente, com pessoas que sejam competentes e responsáveis por verificar todas as irregularidades que venham a surgir ao longo do processo eleitoral.

Através desse estudo pretendeu-se aumentar as discussões sobre o marketing político e o papel das campanhas políticas dentro das instituições de ensino. Assim como, incentivar uma maior participação da comunidade nas eleições e melhoria no desenvolvimento do processo eleitoral.

\section{REFERÊNCIAS}

ALMEIDA, Ivana C.; SETTE, Ricardo de S. Marketing Político: A arte e a ciência - XXXIV Encontro da ANPAD - Rio de Janeiro/ RJ - 25 a 29 de setembro/ 2010.

BARDIN, Laurence. Análise de conteúdo. Lisboa: Edições 70, 1977.

FIGUEIREDO, R. O que é marketing político. São Paulo: Brasiliense, 1994.

GIL, Antônio C. Como elaborar projetos de pesquisa. - 5. ed. - São Paulo: Atlas, 2010.

MALHOTRA, Naresh. Pesquisa de Marketing: uma orientação aplicada. Trad. Nivaldo Montigelli Jr. e Alfredo Neves de Farias. - 3. Ed. - Porto Alegre: Bookman, 2001.

MOZZATO, A. R; GRZYBOVSKI, D.; TEIXEIRA, A. N. Análises Qualitativas nos Estudos Organizacionais: As vantagens no uso do software NVivo®. Revista Alcance, v.23, n.4, p.578-587, 2016. 
RAFFA, Claudia; MALIK, Ana Maria; PINHOCHET, Luis Hernan Contreras. Análise das variáveis do ambiente interno no gerenciamento de leitos em organizações hospitalares privadas: aplicação do software NVivo®. V.14, n.4, 2017.

RIBEIRO, R.M. Marketing Político - O poder da estratégia nas campanhas eleitorais. Belo Horizonte: Editora Arte, 2002.

SCOTTO, Maíra G. Encontros e Desencontros entre a política e o mercado: uma antropologia das "trocas" no espaço do marketing político. Horizontes Antropológicos, Porto Alegre, ano 9, n.19, p.49-77, julho de 2003.

TEIXEIRA, Dilma. Marketing político e eleitoral: uma proposta com ética e eficiência. Osasco, São Paulo: Novo Século, 2006. 